TITLE:

\title{
Quantitative analysis of agglomerates levitated from particle layers in a strong electric field
}

\section{$\operatorname{AUTHOR}(\mathrm{S}):$}

Shoyama, Mizuki; Nishida, Shuhei; Matsusaka, Shuji

\section{CITATION:}

Shoyama, Mizuki ... [et al]. Quantitative analysis of agglomerates levitated from particle layers in a strong electric field. Advanced Powder Technology 2019, 30(10): 2052-2058

\section{ISSUE DATE:}

2019-10

URL:

http://hdl.handle.net/2433/243874

\section{RIGHT:}

(c) 2019. This manuscript version is made available under the CC-BY-NC-ND 4.0 license

http://creativecommons.org/licenses/by-nc-nd/4.0/; The full-text file will be made open to the public on 1 October 2021 in accordance with publisher's 'Terms and Conditions for Self-Archiving'.; この論文は出版社版でありません。引用の際 には出版社版をご確認ご利用ください。; This is not the published version. Please cite only the published version. 
Original Research Paper

\section{Quantitative analysis of agglomerates levitated from particle layers in a strong electric} field

Mizuki Shoyama, Shuhei Nishida, Shuji Matsusaka*

Department of Chemical Engineering, Kyoto University, Kyoto 615-8510, Japan

\section{ABSTRACT}

The electrification, agglomeration, and levitation of particles in a strong electric field were analyzed experimentally and theoretically. Particle layers of glass, alumina, and ferrite were formed on a plate electrode and an external voltage was applied. Microscopic observations of the agglomerates levitated from the particle layers revealed that the number of primary particles constituting an agglomerate is affected by particle diameter and electrical resistance, but not by the applied electric field. The electric field distributions in the system were calculated by considering the charges and geometries of the agglomerates formed on the particle layers. The charges of the agglomerates were obtained experimentally. All forces acting on the agglomerates (i.e., gravitational forces, Coulomb forces, interaction forces between polarized particles, image forces, and gradient forces) were analyzed under different conditions, including various electric field distributions and charges of agglomerates. Furthermore, the critical conditions for the levitation of the agglomerates were evaluated using a force balance.

Keywords:

Electrification; Agglomeration; Levitation; Particle layer; External electric field

* Corresponding author.

E-mail address: matsu@cheme.kyoto-u.ac.jp (S. Matsusaka). 


\section{Introduction}

In powder handling processes, the deposition of charged particles is a common occurrence. The accumulation of charged particles on surfaces typically reduces operability and leads to lower productivity. Additionally, electrostatic discharge from charged particles can cause fire and explosion hazards, meaning charged particles must be removed from surfaces. Fluid flow [1, 2] and vibration $[3,4]$ are effective methods for removing particles. Another effective method is the application of an external electric field, which enables remote control of the motion of particles [5-7].

Electrically conductive particles that come into contact with parallel plate electrodes are highly charged with the same polarity as the electrode. This phenomenon is called induction charging [8, 9] and can occur for both semiconductive and dielectric particles [10]. Consequently, sufficiently charged particles are levitated from the electrode by Coulomb forces and begin moving toward the counter electrode. When the particles come into contact with the counter electrode, their polarity is inverted by induction charging. Consequently, the particles move back to the first electrode and then oscillate between the parallel electrodes [9]. Highly conductive particles are charged immediately after contacting electrodes. As the conductivity of the particles decreases, the charging time increases [10-13] and the period of the oscillation cycle increases. However, if electrical resistance is extremely high, induction charging will not occur. Instead, contact charging will dominate $[14,15]$. Because the quantity of charge transferred by one contact charging event is typically small, particles cannot be levitated.

In the particle oscillation system described above, there are both positive and negative charged particles between the electrodes. One method for extracting particles with a unipolar charge from the parallel electrodes is to replace one of the plate electrodes with a mesh electrode [16], which allows particles to pass through the openings [17]. It is worth noting that unipolar 
charged particles experience electrostatic repulsion, meaning this technique is mostly applicable to dispersions $[18,19]$.

Dielectric particles are polarized in an electric field and tend to form chain agglomerates along the electric field direction based on the interactions between polarized particles [20-23]. Electrorheological (ER) fluids, which are suspensions of dielectric particles dispersed in insulating liquids, change their apparent viscosity by forming chain-like structures of particles aligned along the electric field [24]. Although the flow behavior of ER fluids has been studied thoroughly, the induction charging and behavior of dielectric particles in gases have not been studied in detail.

Shoyama and Matsusaka [25] conducted experiments on particle levitation in gases using a parallel electrode system consisting of an upper mesh electrode and lower plate electrode. When an electric field was applied between the electrodes, chain agglomerates levitated from the particle layers. Particle charges were calculated based on motion analysis of the agglomerates in the electric field. The separation forces for particle levitation were also analyzed. Additionally, the mechanisms of particle charging and the agglomeration of particles were elucidated based on experimental results and theoretical analysis. Shoyama and Matsusaka [26] also elucidated the mechanism of the disintegration of agglomerates based on rotation in a non-uniform electric field around the upper mesh electrode. However, quantitative analysis of agglomeration, levitation, and disintegration under various conditions has not been performed.

In this study, we used an experimental setup similar to that in our previous studies [25, 26]. The effects of particle diameter, particle electrical resistance, and applied electric field on electrification, agglomeration, and levitation were analyzed. The various forces acting on the agglomerates were also identified. Furthermore, a force balance was used to evaluate the critical conditions for the levitation of agglomerates. 


\section{Experimental setup and procedure}

Fig. 1 shows the experimental setup used in this study. A removable upper electrode (external dimensions: $60 \times 60 \mathrm{~mm}$, wire diameter: $0.60 \mathrm{~mm}$, opening: $3.63 \mathrm{~mm}$, material: stainless steel, JIS-SUS304) was placed in parallel with a lower plate electrode (external dimensions: $60 \times 60$ mm, material: JIS-SUS304) at a distance of $10 \mathrm{~mm}$. A small number of particles were deposited by gravity onto the lower electrode and particle layers with a thickness of $1 \mathrm{~mm}$ were formed. The lower electrode was then connected to a power supply (10/10B-HS, Trek, Inc.) and the upper electrode was grounded. The voltage applied to the lower electrode was set to $V_{\mathrm{L}}=4,5$, or $6 \mathrm{kV}$, where particles can be stably levitated by induction charging, generating an electric field between the electrodes with upward directionality. The behavior of the particles levitated from the particle layers was recorded by a high-speed camera (FASTCAM Mini UX100, Photron, Ltd.) with a high-magnification zoom lens (VSZ-10100, VS Technology Corporation) at a $5000 \mathrm{fps}$. A metal halide lamp (LS-M250, Sumita Optical Glass, Inc.) was used as a light source.

Fig. 2 shows scanning electron microscopy (SEM) images of three types of sample particles: a glass bead, alumina particle, and ferrite particle. These particles have different surface roughness characteristics but are all approximately spherical. Table 1 lists the properties of the samples (i.e., the mass median diameter $D_{\mathrm{p} 50}$, geometric standard deviation of particle diameter $\sigma_{\mathrm{g}}$, electrical resistance $\rho_{\mathrm{v}}$, and particle density $\rho_{\mathrm{p}}$ ). The electrical resistance of the packed particles was measured under a normal stress of $5 \mathrm{MPa}$.

The particles were dried at $120{ }^{\circ} \mathrm{C}$ for $12 \mathrm{~h}$ and cooled to room temperature in a desiccator prior to experimentation. All experiments were conducted under ambient conditions at a room temperature of $25 \pm 5^{\circ} \mathrm{C}$ and relative humidity of $30 \pm 5 \%$.

\section{Image analysis of levitated particles}


Fig. 3 shows captured images of particles levitated from different particle layers at $V_{\mathrm{L}}=5$ kV. For the glass beads (Fig. 3a) and alumina particles (Fig. 3b), large numbers of both single particles and chain agglomerates were levitated. This state is similar to that observed in our previous study [25]. In contrast, for the ferrite particles (Fig. 3c), very few chain agglomerates were levitated. This difference implies that the state of particle levitation depends on material characteristics. To analyze the states and motions of particles, clearly focused objects were selected.

Fig. 4 shows the cumulative distributions of the number of primary (single) particles constituting an agglomerate and single particles levitated from the different particle layers at $V_{\mathrm{L}}$ $=5 \mathrm{kV}$. The sample size for each statistical analysis is 300 that is the number of particles for each material. The ratio of single particle levitation to total levitation is approximately $60 \%$ for the glass beads $\left(D_{\mathrm{p} 50}=61 \mu \mathrm{m}\right)$. As the number of primary particles in an agglomerate increases, the ratio of agglomerates decreases. For the ferrite particles $\left(D_{\mathrm{p} 50}=63 \mu \mathrm{m}\right)$, the ratio of single particle levitation is approximately $90 \%$. The ratio of single particle levitation for the alumina particles $\left(D_{\mathrm{p} 50}=80 \mu \mathrm{m}\right)$ lies in the intermediate region between the other two types of particles. These differences are likely caused by differences in the electrical resistances of the particles. Low electrical resistance material is immediately charged up by induction, while high electrical resistance one takes time [10-13]. For the former, even single particles can be easily levitated because of excessive charges on the surfaces.

Fig. 5 shows the effects of primary particle diameter on agglomeration. Experiments were carried out at $V_{\mathrm{L}}=5 \mathrm{kV}$ using three different sizes of glass beads. For $D_{\mathrm{p} 50}=44 \mu \mathrm{m}$, the ratio of single particle levitation to total levitation is approximately $40 \%$. For $D_{\mathrm{p} 50}=104 \mu \mathrm{m}$, the ratio is approximately $70 \%$. The ratio for $D_{\mathrm{p} 50}=61 \mu \mathrm{m}$ lies in the intermediate region between the two values above. These experimental results also demonstrate that the number of primary particles 
decreases with an increase in primary particle diameter because the gravitational force acting on the particles become relatively larger than the interaction forces for agglomerate formation.

Fig. 6 shows the effects of applied voltage on agglomeration. Experiments were carried out using glass beads with $D_{\mathrm{p} 50}=61 \mu \mathrm{m}$ at $V_{\mathrm{L}}=4,5$, and $6 \mathrm{kV}$. The experimental results demonstrate that applied voltage has little effect on the number of primary particles. Therefore, the critical force balance for particle levitation is nearly constant with different applied voltages.

\section{Motion analysis of charged particles}

In this section, we describe a theoretical approach for analyzing the motion of charged agglomerates in an electric field based on the findings of previous studies [19, 25, 26]. A straightchain agglomerate moving in an electric field experiences a drag force $\mathbf{F}_{\mathrm{d}}$, gravitational force $\mathbf{F}_{\mathrm{g}}$, and electrostatic force $\mathbf{F}_{\mathrm{e}}$. The equation of motion of an agglomerate is expressed as

$$
n m_{\mathrm{p}} \frac{\mathrm{d} \mathbf{v}_{\mathrm{a}}}{\mathrm{d} t}=\mathbf{F}_{\mathrm{d}}+\mathbf{F}_{\mathrm{g}}+\mathbf{F}_{\mathrm{e}}
$$

where $n$ is the number of the primary particles constituting the agglomerate, $m_{\mathrm{p}}$ is the mass of each primary particle, $\mathbf{v}_{\mathrm{a}}$ is the velocity of the agglomerate, and $t$ is time. The mass of each particle is defined as

$$
m_{\mathrm{p}}=\frac{\pi D_{\mathrm{p}}^{3} \rho_{\mathrm{p}}}{6}
$$

where $D_{\mathrm{p}}$ is the particle diameter and $\rho_{\mathrm{p}}$ is the particle density. For a stationary fluid, $\mathbf{F}_{\mathrm{d}}$ is given by $[27,28]$

$$
\mathbf{F}_{\mathrm{d}}=3 \pi \mu D_{\mathrm{a}} \mathbf{v}_{\mathrm{a}} \kappa,
$$

where $\mu$ is the viscosity of the fluid and $D_{\mathrm{a}}$ is the volume equivalent diameter of the agglomerate, which is defined as 


$$
D_{\mathrm{a}}=n^{\frac{1}{3}} D_{\mathrm{p}}
$$

$\kappa$ is a dynamic shape factor defined as

$$
\kappa=\left\{\begin{array}{ll}
1.00 & (n=1) \\
1.03 & (n=2) \\
1.07 & (n=3)
\end{array} .\right.
$$

The gravitational force of the agglomerate is defined as

$$
\mathbf{F}_{\mathrm{g}}=n m_{\mathrm{p}} \mathbf{g},
$$

where $\mathbf{g}$ is the gravitational acceleration. $\mathbf{F}_{\mathrm{e}}$ is the electrostatic force consisting of the Coulomb force in the external electric field $\mathbf{F}_{\text {ex }}$, image force $\mathbf{F}_{\mathrm{i}}$, interaction force between polarized particles $\mathbf{F}_{\mathrm{p}}$, and gradient force in a non-uniform electric field $\mathbf{F}_{\text {grad, }}$, which is defined as

$$
\mathbf{F}_{\mathrm{e}}=\mathbf{F}_{\mathrm{ex}}+\mathbf{F}_{\mathrm{i}}+\mathbf{F}_{\mathrm{p}}+\mathbf{F}_{\text {grad }} \text {. }
$$

Here, $\mathbf{F}_{\text {ex }}$ is expressed as

$$
\mathbf{F}_{\mathrm{ex}}=\sum_{i=1}^{n} \mathbf{F}_{\mathrm{q} i},
$$

where $\mathbf{F}_{\mathrm{q} i}$ is the Coulomb force acting on the $i$-th particle in the chain agglomerate, which is defined as

$$
\mathbf{F}_{\mathrm{q} i}=q_{i} \mathbf{E}_{\mathrm{ex}},
$$

where $q_{i}$ is the charge of the $i$-th particle and $\mathbf{E}_{\mathrm{ex}}$ is the external electric field. $\mathbf{F}_{\mathrm{i}}$ is expressed as [29]

$$
\mathbf{F}_{\mathrm{i}}=\frac{1}{16 \pi \varepsilon_{\mathrm{rf}} \varepsilon_{0}} \cdot \frac{\varepsilon_{\mathrm{rs}}-\varepsilon_{\mathrm{rf}}}{\varepsilon_{\mathrm{rs}}+\varepsilon_{\mathrm{rf}}} \sum_{i=1}^{n} \frac{q_{i}^{2}}{z_{\mathrm{pi}}^{2}}
$$

where $\varepsilon_{0}$ is the vacuum permittivity, $\varepsilon_{\mathrm{rf}}$ is the relative permittivity of the fluid, $\varepsilon_{\mathrm{rs}}$ is the relative permittivity of the particle layers, and $z_{\mathrm{p} i}$ is the position of the $i$-th particle on the top surface of the particle layers in the $z$ direction. When the axis of the chain agglomerate is parallel to the external electric field, $\mathbf{F}_{\mathrm{p}}$ is expressed as [24] 


$$
\mathbf{F}_{\mathrm{p}}=\frac{3}{8} \pi \varepsilon_{0} \varepsilon_{\mathrm{rf}}\left(\frac{\varepsilon_{\mathrm{rp}}-1}{\varepsilon_{\mathrm{rp}}+2}\right)^{2}\left(\frac{D_{\mathrm{p}}}{d}\right)^{4} D_{\mathrm{p}}^{2} \mathbf{E}_{\mathrm{ex}}^{2},
$$

where $\varepsilon_{\mathrm{rp}}$ is the relative permittivity of the particle.

$\mathbf{F}_{\text {grad }}$ is expressed as [30]

$$
\mathbf{F}_{\text {grad }}=\frac{1}{4} \pi \varepsilon_{0} \varepsilon_{\mathrm{rf}} \frac{\varepsilon_{\mathrm{rp}}-1}{\varepsilon_{\mathrm{rp}}+2} D_{\mathrm{a}}^{3} \operatorname{grad} \mathbf{E}_{\mathrm{ex}}^{2} .
$$

\section{Electric field calculation}

To analyze the motion of agglomerates under various electrostatic conditions, electric field strengths were calculated in a 3D Cartesian coordinate system $(x, y, z)$ using the finite element method (COMSOL Multiphysics, AB/COMSOL, Inc.). The governing equations were solved using the Galerkin method

Fig. 7 shows a simulation model that is used to calculate an electric field between electrodes with 1-mm-thick particle layers, as well as an enlarged view around the top surfaces of the particle layers. The calculation domain is set to $5 D_{\mathrm{p}} \times 3 \sqrt{3} D_{\mathrm{p}}$ for the horizontal cross section and $10 \mathrm{~mm}$ for the height, which is the same as the vertical distance between the electrodes in our experimental setup. The origin (i.e., $(x, y, z)=(0,0,0))$ is positioned at the center of the bottom surface. The top and bottom boundaries are set to zero and a given voltage, respectively. Periodic boundary conditions are applied at the side boundaries. The number of elements was more than 600,000 . The grid size is set to $0.1 \mathrm{~mm}$ on the particle layer surfaces and increased toward the top of the domain to reduce the total calculation load.

For the conditions of $V_{\mathrm{L}}=5 \mathrm{kV}, \varepsilon_{\mathrm{rp}}=7$, and $D_{\mathrm{p}}=60 \mu \mathrm{m}$, the electric field strength in the $\mathrm{z}$ direction, denoted $E_{\text {exz }}$, is $540 \mathrm{kV} / \mathrm{m}$ in the free space. This calculated value is $8 \%$ larger than 500 $\mathrm{kV} / \mathrm{m}$, which is the value with no particle layers between the electrodes. This disparity of $8 \%$ is consistent, regardless of the applied voltage. When the values of $\varepsilon_{\mathrm{rp}}$ and $D_{\mathrm{p}}$ are changed within 
the experimental range, the variation of $E_{\mathrm{exz}}$ remains within a few percent.

\section{Evaluation of particle charges and forces acting on agglomerates}

Fig. 8a shows a series of images of particle agglomeration $(t \leq 0)$ and levitation $(t>0)$ from a 1-mm-thick particle layer (glass beads, $D_{\mathrm{p}}=100 \mu \mathrm{m}$ ). A chain agglomerate consisting of three primary particles levitates upward. Fig. 8b shows the experimental data (open circles) for the position of the levitated agglomerate in the $z$ direction. The solid and broken lines in this figure are theoretical particle trajectories. They were calculated using Eq. (1) with $E_{\mathrm{exz}}=540 \mathrm{kV} / \mathrm{m}$ which was obtained in section 5. The experimental data agree well with the broken line, which was calculated with a charge of $0.135 \mathrm{pC}$. The charges of the other agglomerates were determined in the same manner.

Fig. 9 shows the relationships between the experimental values of $\sum q_{\mathrm{i}}$, which represent the charges of levitated agglomerates ( $n=2$ or 3 ) or individual particles $(n=1)$, and $D_{\mathrm{p} 50}$. Experiments were carried out using glass beads at $V_{\mathrm{L}}=5 \mathrm{kV}$. The $\sum q_{\mathrm{i}}$ values increase with an increase in $D_{\mathrm{p} 50}$ and/or $n$ values.

Fig. 10 shows the effects of $V_{\mathrm{L}}$ on $\sum q_{\mathrm{i}}$. The values of $\sum q_{\mathrm{i}}$ are constant, regardless of $V_{\mathrm{L}}$, in a range of $4-6 \mathrm{kV}$. The charge of a primary particle $q_{\mathrm{i}}$ in an agglomerate decreases with an increase in $n$.

To analyze the electrostatic forces acting on agglomerates just prior to their separation from particle layers, both the electric field around the particles and the charges of the agglomerates must be determined. Fig.11a shows a simulation of a chain agglomerate $\left(D_{\mathrm{p}}=60 \mu \mathrm{m}\right.$ and $\left.n=3\right)$ on the top surface of the particle layers shown in Fig. 7. The charges of the primary particles in the agglomerate and the top particle layer are assumed to be $q=0.017 \mathrm{pC}$ based on the experimental result for $n=3$ at $V_{\mathrm{L}}=5 \mathrm{kV}$ (see Fig. 9). Fig.11b shows the calculated electric field 
strength in the $z$ direction, denoted $E_{\text {exz }}$, along the axis of the chain agglomerate at $V_{\mathrm{L}}=5 \mathrm{kV}$ and $\varepsilon_{\mathrm{rp}}=7$. The charge of the top particle layer weakens the electric field in the region of $z<1 \mathrm{~mm}$. Consequently, the $E_{\text {exz }}$ value is nearly zero, although there are small fluctuations caused by particle arrangements. This implies that the particles in this region do not have charges in an electrostatic equilibrium state, meaning induction charging occurs only on the top particle layer and agglomerates $(n=3)$. In contrast, the $E_{\text {exz }}$ values within the agglomerate $(z=1-1.18 \mathrm{~mm})$ fluctuate significantly and are relatively high at the particle contact points and on the top surface of the agglomerate. The $E_{\text {exz }}$ value in the free space $(z>1.3 \mathrm{~mm})$ is constant and is $3.6 \%$ greater than the value with no agglomerate.

Fig. 12a shows the volume average, which is calculated in the volume of a particle, of the electric field strength in the $z$ direction $\left\langle E_{\text {exz }}>\right.$ for each primary particle $\left(n_{p}=1-3\right)$ in the agglomerate and the top particles in the particle layers $\left(n_{\mathrm{p}}=0\right)$ at $V_{\mathrm{L}}=5 \mathrm{kV}$, where $n_{\mathrm{p}}$ is the ordinal number of particles, which is related to particle height. For the top and bottom particles of the agglomerate, $n_{\mathrm{p}}=3$ and 1 , respectively. For $n_{\mathrm{p}}=0$, the $<E_{\mathrm{exz}}>$ values are smaller than 100 $\mathrm{kV} / \mathrm{m}$, while for $n_{\mathrm{p}}=1-3$, the $<E_{\text {exz }}>$ values are larger than $200 \mathrm{kV} / \mathrm{m}$. The effect of $D_{\mathrm{p}}$ on $<E_{\text {exz }}>$ is relatively small. Fig. $12 \mathrm{~b}$ shows the effect of $V_{\mathrm{L}}$ on $\left\langle E_{\mathrm{exz}}>\right.$. Although the relationship between $<E_{\text {exz }}>$ and $n_{\mathrm{p}}$ is similar to that shown in Fig. 12a, $<E_{\text {exz }}>$ increases with an increase in $V_{\mathrm{L}}$. A remarkable feature is that the agglomerate exists in a larger electric field, meaning it is expected that the agglomerate will experience larger electrostatic forces.

To clarify the conditions for the formation and levitation of an agglomerate $(n=3)$, the forces acting on the bottom particle $\left(n_{\mathrm{p}}=1\right)$ of the agglomerate just prior to its separation from the particle layers were calculated using the equations presented in Section 4. Here, the gravitational force $F_{\mathrm{g}}$ and electrostatic attractive forces between particles (i.e., the image force $F_{\mathrm{i}}$ and interaction forces between polarized particles $F_{\mathrm{p}}$ ) act downward, while the Coulomb force $F_{\text {ex }}$ and 
gradient force $F_{\text {grad }}$ act upward. Because interparticle forces, such as van der Waals forces, are relatively small under dynamic conditions during agglomeration and levitation, we excluded these forces from our analysis.

Fig. 13 shows the relationship between the forces acting on an agglomerate $(n=3)$ just prior to its separation from the particle layers and $D_{\mathrm{p} 50} . F_{\mathrm{g}}$ is dominant among the downward forces $\left(F_{\mathrm{g}}, F_{\mathrm{i}}\right.$, and $F_{\mathrm{p}}$ : closed symbols) and $F_{\mathrm{ex}}$ is dominant among the upward forces ( $F_{\mathrm{ex}}, F_{\text {grad: }}$ open symbols). The difference between the upward and downward forces becomes larger for smaller particle diameters. The total upward force must exceed the total downward force to levitate an agglomerate. The charge transferred to the particles by induction can increase based on a time lag in the responses following the establishment of the force balance of particle levitation. However, the reverse state of the force balance can also be observed for larger particles $\left(D_{\mathrm{p} 50}=\right.$ $104 \mu \mathrm{m})$. This is likely caused by low charge transfer per unit time and unit surface area, as well as experimental and statistical errors.

Fig. 14 shows the effect of $V_{\mathrm{L}}$ on the forces acting on an agglomerate just prior to its separation from the particle layers with $D_{\mathrm{p} 50}=61 \mu \mathrm{m} . F_{\mathrm{ex}}$ and $F_{\mathrm{g}}$ are dominant as downward and upward forces, respectively, and the $F_{\mathrm{ex}}$ values are larger than the $F_{\mathrm{g}}$ values. As the value of $V_{\mathrm{L}}$ increases, the $F_{\text {ex }}$ value also increases. Additionally, $F_{\mathrm{p}}$ increases to balance the upward and downward forces. At $V_{\mathrm{L}}=6 \mathrm{kV}$, the ratio of $F_{\mathrm{p}}$ to $F_{\mathrm{g}}$ is as large as $18 \%$. $F_{\mathrm{p}}$ should also be considered for force balancing at higher applied voltages because $F_{\mathrm{p}}$ is proportional to $E_{\mathrm{ex}}{ }^{2}$ (Eq. (11)), while $F_{\text {ex }}$ is proportional to $E_{\text {ex }}$ (Eqs. (8) and (9)).

\section{Conclusions}

The electrification, agglomeration, and levitation of particles in a strong electric field were studied experimentally and theoretically with a focus on the effects of particle diameter, particle 
electrical resistance, and applied electric voltage or applied electric field. The results obtained can be summarized as follows:

(1) Particles with relatively high electrical resistance tend to form chain agglomerates on particle layers in a strong electric field. These agglomerates are then levitated. In contrast, particles with lower electrical resistance are levitated as single particles without agglomeration.

(2) The number of primary particles constituting an agglomerate, denoted $n$, increases with a decrease in primary particle diameter, denoted $D_{\mathrm{p}}$, but is not affected by the applied electric field strength when it is sufficiently strong.

(3) The charge of levitated agglomerates increases with an increase in $D_{\mathrm{p}}$ and/or $n$, but is not affected by the electric field strength. The charge of a primary particle in an agglomerate decreases with an increase in $n$.

(4) The gravitational force $F_{\mathrm{g}}$, image force $F_{\mathrm{i}}$, and polarization force $F_{\mathrm{p}}$ act downward, while the Coulomb force $F_{\text {ex }}$ and gradient force $F_{\text {grad }}$ act upward. The dominant forces are $F_{\mathrm{g}}$ and $F_{\text {ex. }}$ In a strong electric field, $F_{\mathrm{p}}$ should also be considered.

(5) To levitate agglomerates, the total upward force must exceed the total downward force. The difference between the upward and downward forces becomes larger for smaller particle diameters.

\section{Acknowledgement}

This research was supported by JSPS KAKENHI Grant Number JP17H03442. 


\section{Nomenclature}

$D_{\mathrm{a}} \quad$ volume equivalent diameter of an agglomerate (m)

$D_{\mathrm{p}} \quad$ particle diameter (m)

$D_{\mathrm{p} 50} \quad$ mass median diameter (m)

$d \quad$ distance between particle centroids (m)

$\mathbf{E}_{\text {ex }} \quad$ external electric field (V/m)

$E_{\text {exz }} \quad$ external electric field strength in the $z$ direction $(\mathrm{V} / \mathrm{m})$

$<E_{\text {exz }}>\quad$ volume average of external electric field strength in the $z$ direction $(\mathrm{V} / \mathrm{m})$

$F(n) \quad$ discrete cumulative distribution (-)

$\mathbf{F}_{\mathrm{d}} \quad$ drag force (N)

$\mathbf{F}_{\mathrm{e}} \quad$ electrostatic force (N)

$\mathbf{F}_{\mathrm{ex}} \quad$ Coulomb force in an external electric field (N)

$\mathbf{F}_{\mathrm{g}} \quad$ gravitational force (N)

$\mathbf{F}_{\text {grad }} \quad$ gradient force in a non-uniform electric field (N)

$\mathbf{F}_{\mathrm{i}} \quad$ image force (N)

$\mathbf{F}_{\mathrm{p}} \quad$ interaction force between polarized particles (N)

$\mathbf{F}_{\mathrm{q} i} \quad$ Coulomb force acting on the $i$-th particle in a chain agglomerate (N)

g gravitational acceleration $\left(\mathrm{m} / \mathrm{s}^{2}\right)$

$m_{\mathrm{p}} \quad$ mass of a primary particle $(\mathrm{kg})$

$n \quad$ number of primary particles constituting an agglomerate or single particle (-)

$n_{p} \quad$ ordinal number of particles, which is related to particle height in an agglomerate (-)

$q \quad$ particle charge (C)

$t \quad$ time (s) 
$\mathbf{v}_{\mathrm{a}} \quad$ velocity of an agglomerate $(\mathrm{m} / \mathrm{s})$

$V_{\mathrm{L}} \quad$ voltage applied to the lower electrode (V)

$x \quad$ horizontal coordinate (m)

$y \quad$ horizontal coordinate perpendicular to the $x$ coordinate (m)

vertical coordinate (m)

$Z_{\mathrm{p}}$

particle position in the $z$ direction (m)

$\varepsilon_{0}$

vacuum permittivity $(\mathrm{F} / \mathrm{m})$

$\varepsilon_{\mathrm{rf}}$

relative permittivity of a fluid (-)

$\varepsilon_{\mathrm{rp}}$

relative permittivity of a particle (-)

$\varepsilon_{\text {rs }} \quad$ relative permittivity of particle layers (-)

$\kappa$

dynamic shape factor $(-)$

$\mu$

viscosity of a fluid $(\mathrm{Pa} \cdot \mathrm{s})$

$\rho_{\mathrm{p}} \quad$ particle density $\left(\mathrm{kg} / \mathrm{m}^{3}\right)$

$\rho_{\mathrm{v}} \quad$ volume resistivity of samples $(\Omega \cdot \mathrm{m})$

$\sigma_{\mathrm{g}} \quad$ geometric standard deviation of particle diameter (-)

subscripts

i i-th particle in a chain agglomerate 


\section{References}

[1] H. Masuda, K. Gotoh, H. Fukada, Y. Banba, The removal of particles from flat surfaces using a high-speed air jet, Adv. Powder Technol. 5 (1994) 205-217.

[2] K. Gotoh, K. Mizutani, Y. Tsubota, J. Oshitani, M. Yoshida, K. Inenaga, Enhancement of particle removal performance of high-speed air jet by setting obstacle in jet flow, Particul. Sci. Technol. 33 (2015) 567-571.

[3] Kobayakawa, S. Kiriyama, M. Yasuda, S. Matsusaka, Microscopic analysis of particle detachment from an obliquely oscillating plate, Chem. Eng. Sci. 123 (2015) 388-394

[4] M. Adachi, K. Hamazawa, Y. Mimuro, H. Kawamoto, Vibration transport system for lunar and Martian regolith using dielectric elastomer actuator, J. Electrostat. 89 (2017) 88-98.

[5] S. Masuda, K. Fujibayashi, K. Ishida, H. Inaba, Confinement and transportation of charged aerosol clouds via electric curtain, Electr. Eng. Jpn. 92 (1972) 43-52.

[6] C. I. Calle, C. R. Buhler, J. L. McFall, S. J. Snyder, Particle removal by electrostatic and dielectrophoretic forces for dust control during lunar exploration missions, J. Electrostat. 67 (2009) 89-92.

[7] H. Kawamoto, M. Uchiyama, B. L. Cooper, D. S. McKay, Mitigation of lunar dust on solar panels and optical elements utilizing electrostatic traveling-wave, J. Electrostat. 69 (2011) $370-379$.

[8] D. C. Blanchard, Electrically charged drops from bubbles in sea water and their meteorological significance, J. Meteorol. 15 (1958) 383-396.

[9] A. Y. H. Cho, Contact Charging of micron-sized particles in intense electric fields, J. Appl. Phys. 35 (1964) 2561-2564.

[10] Y. Wu, G. S. P. Castle, I. I. Inculet, S. Petigny, G. S. Swei, Induction charge on freely 
levitating particles, Powder technol. 135 (2003) 59-64.

[11] Y. Ohkubo, Y. Takahashi, Lifting criteria of an induction-charged spherical particle in a field with horizontally set parallel plate electrodes, Kagaku Kogaku Ronbun. 22 (1996a) $113-119$.

[12] Y. Ohkubo, Y. Takahashi, Experimental investigation on lifting criteria of an inductioncharged spherical particle in a field with horizontally set parallel plate electrodes, Kagaku Kogaku Ronbun. 22 (1996b) 603-609.

[13] B. F. Nader, G. S. P. Castle, K. Adamiak, Effect of surface conduction on the dynamics of induction charging of particles, J. Electrostat. 67 (2009) 394-399.

[14] S. Matsusaka, H. Maruyama, T. Matsuyama, M. Ghadiri, Triboelectric charging of powders: a review, Chem. Eng. Sci. 65 (2010) 5781-5807.

[15] S. Matsusaka, Control of particle tribocharging, Kona Powder Part. J. 29 (2011) 27-38.

[16] T. Tada, T. Yamamoto, Y, Baba, M. Takeuchi, Ion charging and electron charging to an insulating toner, J. Soc. Powder Technol. Japan 41 (2004) 636-644.

[17] M. Adachi, H. Maezono, H. Kawamoto, Sampling of regolith on asteroids using electrostatic force, J. Aerospace Eng. 29 (2016) 04015081.

[18] H. Masuda, Dry dispersion of fine particles in gaseous phase, Adv. Powder Technol. 20 (2009) 113-122.

[19] M. Shoyama, T. Kawata, M. Yasuda, S. Matsusaka, Particle electrification and levitation in a continuous particle feed and dispersion system with vibration and external electric fields, Adv. Powder Technol. 29 (2018) 1960-1967.

[20] H. E. Hollmann, Semiconductive colloidal suspensions with non-linear properties, J. Appl. Phys. 21 (1950) 402-413.

[21] C. A. R. Pearce, The mechanism of the resolution of water-in-oil emulsions by electrical 
treatment, Brit. J. Appl. Phys. 5 (1954) 136.

[22] T. Itoh, S. Masuda, F. Gomi, Electrostatic orientation of ceramic short fibers in liquid, J. Electrostat., 32 (1994) 71-89.

[23] Y. Nakajima, T. Matsuyama, Electrostatic field and force calculation for a chain of identical dielectric spheres aligned parallel to uniformly applied electric field, J. Electrostat. 55 (2002) 203-221.

[24] M. Parthasarathy, D. J. Klingenberg, Electrorheology: mechanisms and models, Mater. Sci. Eng. R17 (1996) 57-103.

[25] M. Shoyama, S. Matsusaka, Electric charging of dielectric particle layers and levitation of particles in a strong electric field, Kagaku Kogaku Ronbun. 43 (2017) 319-326.

[26] M. Shoyama, S. Matsusaka, Mechanism of disintegration of charged agglomerates in nonuniform electric field, Chem. Eng. Sci. 198 (2019) 155-164.

[27] G. Kasper, T. Niida, M. Yang, Measurements of viscous drag on cylinders and chains of spheres with aspect ratios between 2 and 50, J. Aerosol Sci. 16 (1985) 535-556.

[28] T. Niida, S. Ohtsuka, Dynamic shape factors of regular shaped agglomerates and estimation based on agglomerate symmetry -for rectangular parallelepiped, V-and W-shaped, hexagonal and H-shaped agglomerates, KONA Powder Part. J. 15 (1997) 202-211.

[29] E. Weber, Electromagnetic Fields: Theory and Applications, Vol. I Mapping of Fields, John Wiley \& Sons, New York, (1950) 215-233.

[30] H. Morgan, N. Green, Dielectrophoretic manipulation of rod-shaped viral particles. J. Electrostat. 42 (1997) 279-293. 
Table. 1 Properties of sample particles

\begin{tabular}{lcccc}
\hline Material & $D_{\mathrm{p} 50}(\mu \mathrm{m})$ & $\sigma_{\mathrm{g}}(-)$ & $P_{\mathrm{v}}(\Omega \cdot \mathrm{m})$ & $P_{\mathrm{p}}\left(\mathrm{kg} / \mathrm{m}^{3}\right)$ \\
\hline \multirow{2}{*}{ Glass } & 44 & 1.07 & $3.1 \times 10^{6}$ & \\
& 61 & 1.06 & $10.7 \times 10^{6}$ & 2300 \\
& 104 & 1.04 & $28.3 \times 10^{6}$ & \\
Alumina & 80 & 1.20 & $0.3 \times 10^{6}$ & 3950 \\
Ferrite & 63 & 1.18 & 0.8 & 4850 \\
\hline
\end{tabular}


Fig. 1. Experimental setup.

Fig. 2. SEM images of sample particles.

Fig. 3. Images of particles levitated from particle layers at $V_{\mathrm{L}}=5 \mathrm{kV}$ : (a) glass $D_{\mathrm{p} 50}=61 \mu \mathrm{m}$, (b) alumina $D_{\mathrm{p} 50}=80 \mu \mathrm{m}$, and (c) ferrite $D_{\mathrm{p} 50}=63 \mu \mathrm{m}$.

Fig. 4. Cumulative distributions of the number of primary particles constituting an agglomerate or single particle levitated from particle layers consisting of different materials.

Fig. 5. Effect of primary particle diameter on the degree of agglomeration.

Fig. 6. Effect of applied voltage on the degree of agglomeration.

Fig. 7. Simulation model for calculating the electric field between electrodes with 1-mm-thick particle layers.

Fig. 8. Estimation of the charge of an agglomerate: (a) a series of images of the agglomeration of particles $(t \leq 0)$ and levitation $(t>0)$ from a 1-mm-thick particle layer (glass beads, $D_{\mathrm{p}}=$ $100 \mu \mathrm{m}$ ) and (b) fitting of the experimental data related to levitation.

Fig. 9. Effect of particle diameter on the charge of an agglomerate or single particle.

Fig. 10. Effect of applied voltage on the charge of particles constituting an agglomerate or single particle.

Fig. 11. Calculation of electric field strength: (a) simulation model and (b) calculated results in the $z$ direction along the axis of the chain agglomerate.

Fig. 12. Volume average of electric field strength in the $z$ direction for each particle in the chain 
agglomerate $\left(n_{\mathrm{p}}=1-3\right)$ and the top particles in the particle layers $\left(n_{\mathrm{p}}=0\right)$, where $n_{\mathrm{p}}$ is the ordinal number of particles, which is related to particle height: (a) effect of primary particle diameter $D_{\mathrm{p}}$ and (b) effect of applied voltage $V_{\mathrm{L}}$.

Fig. 13. Relationship between the forces acting on an agglomerate just prior to its separation from a particle layer and particle diameter.

Fig. 14. Effect of applied voltage on the forces acting on an agglomerate just prior to its separation from a particle layer. 


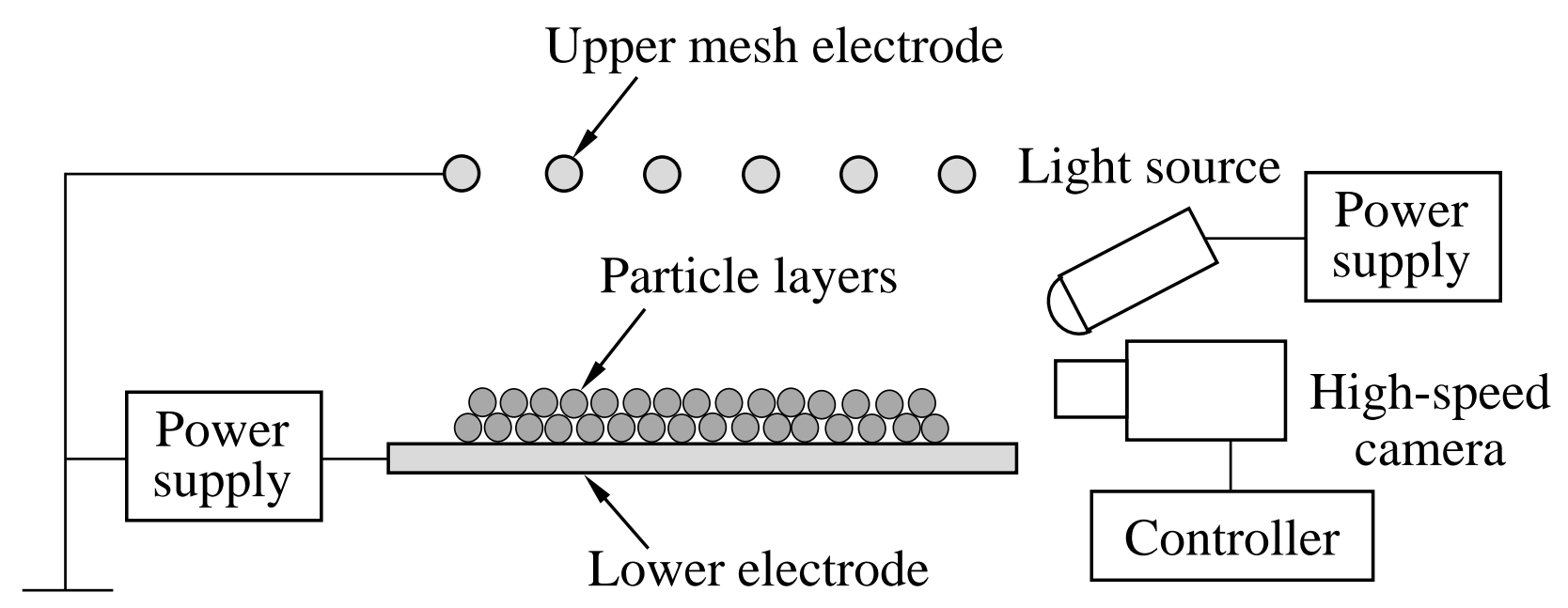

Fig. 1. Experimental setup. 


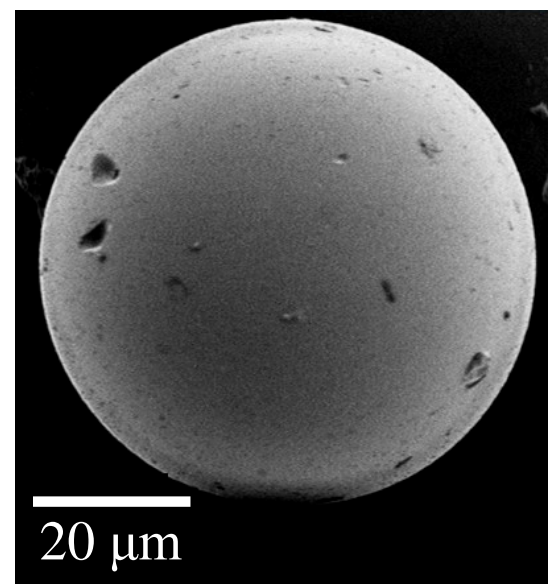

(a) Glass

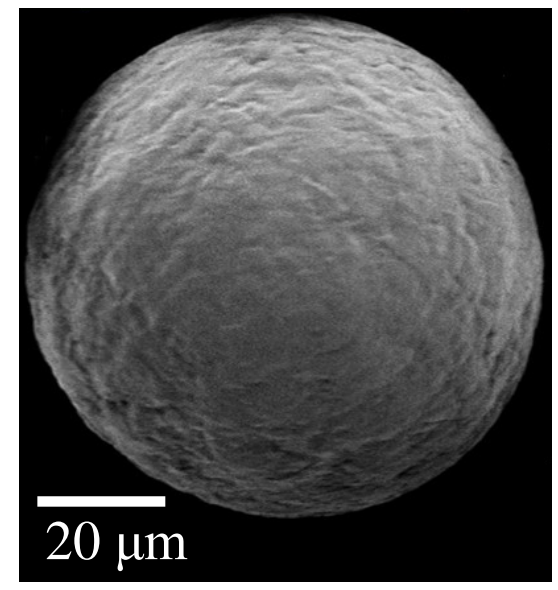

(b) Alumina

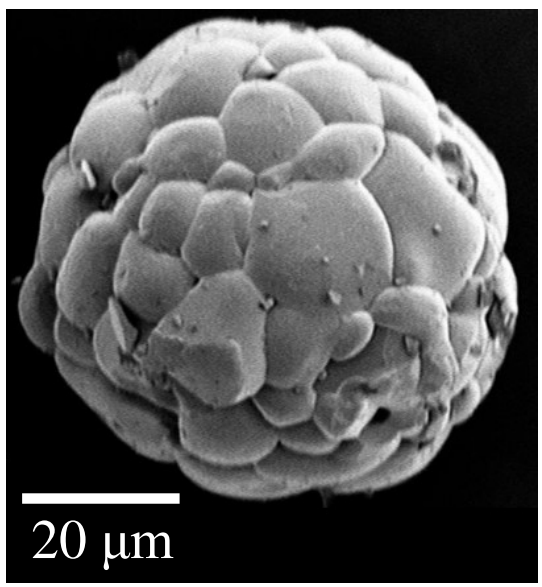

(c) Ferrite

Fig. 2. SEM images of sample particles. 

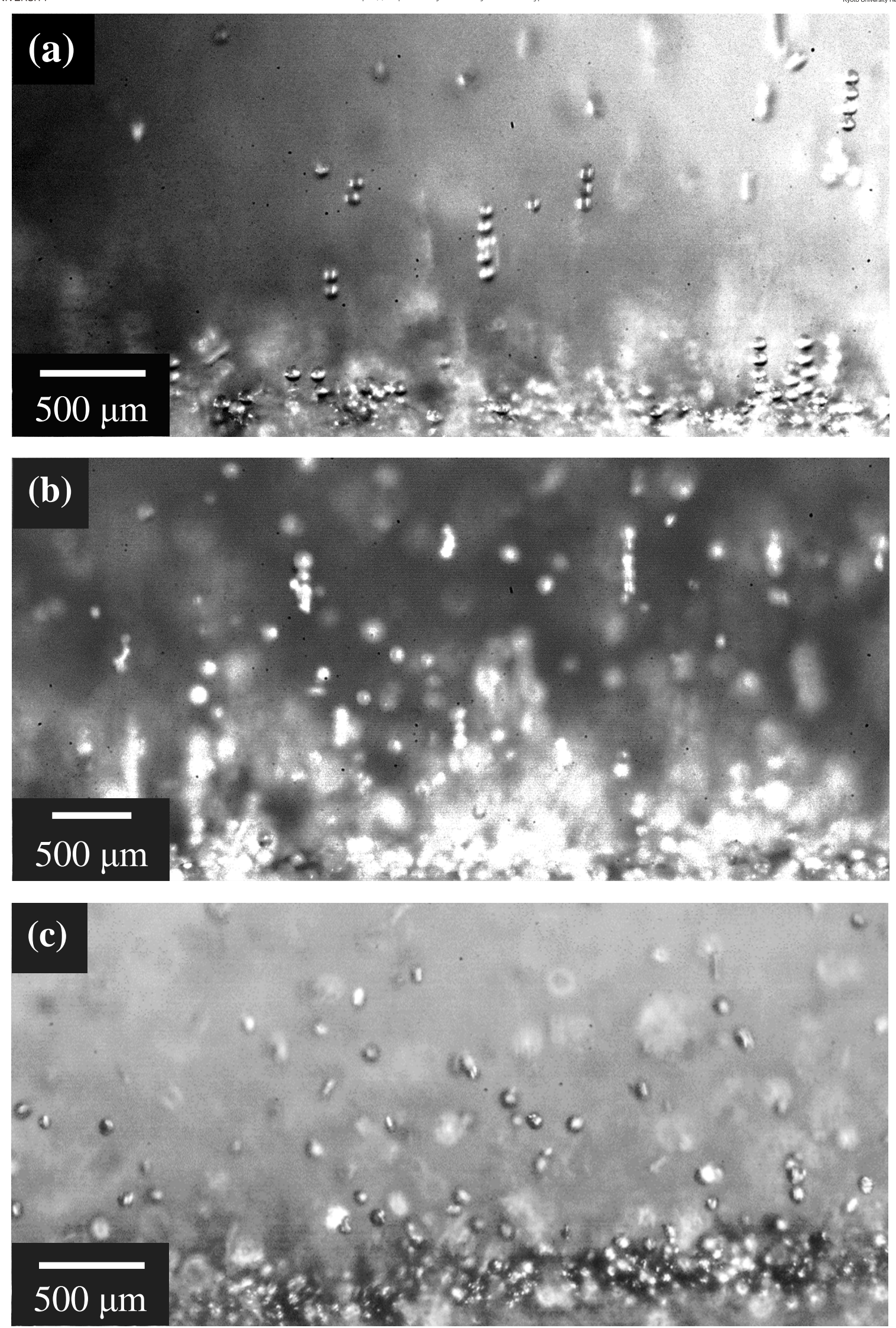

Fig. 3. Images of particles levitated from particle layers at $V_{\mathrm{L}}=5 \mathrm{kV}$ : (a) glass $D_{\mathrm{p} 50}=61 \mu \mathrm{m}$, (b) alumina $D_{\mathrm{p} 50}=80 \mu \mathrm{m}$, and (c) ferrite $D_{\mathrm{p} 50}=63 \mu \mathrm{m}$. 


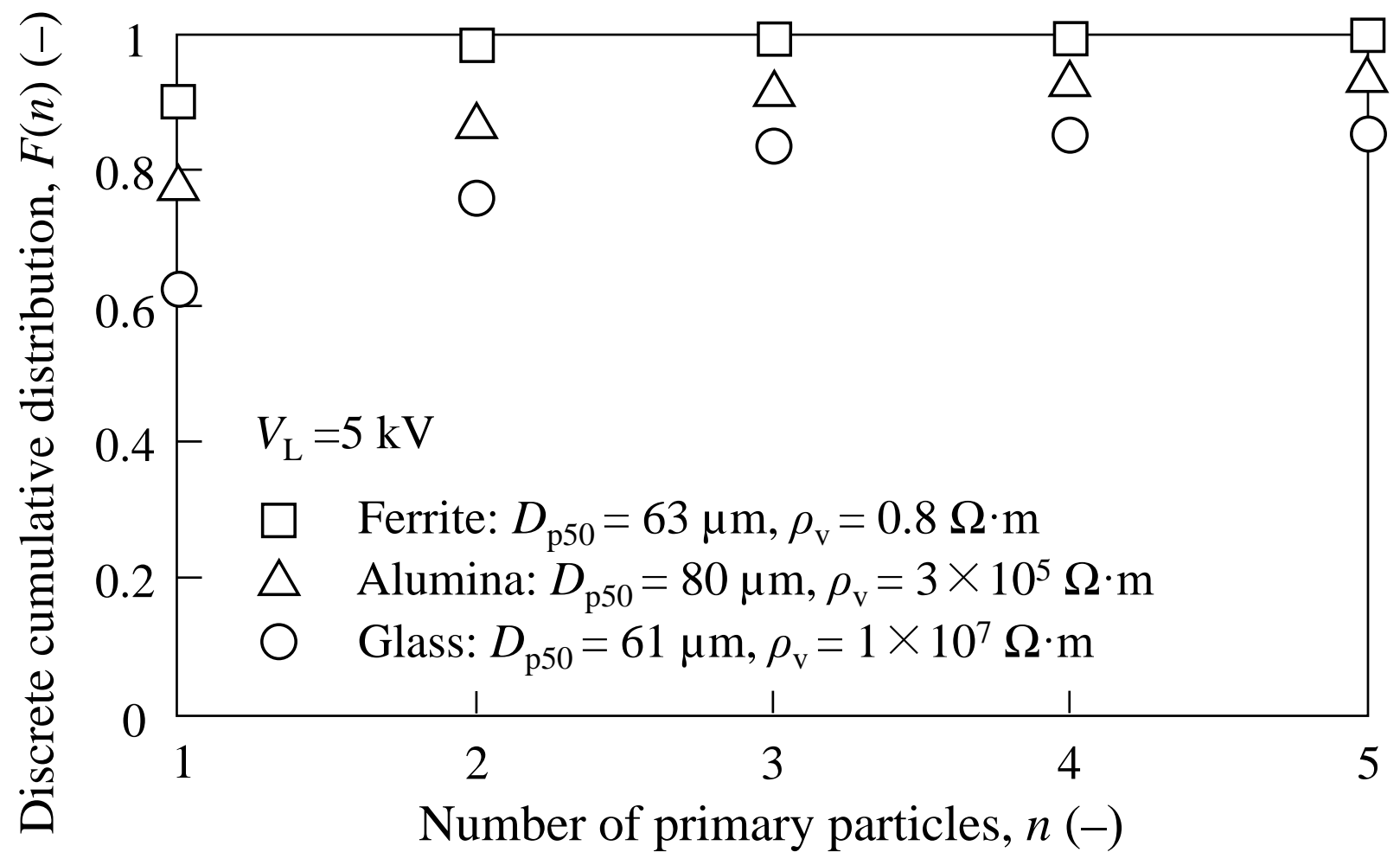

Fig. 4. Cumulative distributions of the number of primary particles constituting an agglomerate or single particle levitated from particle layers consisting of different materials. 


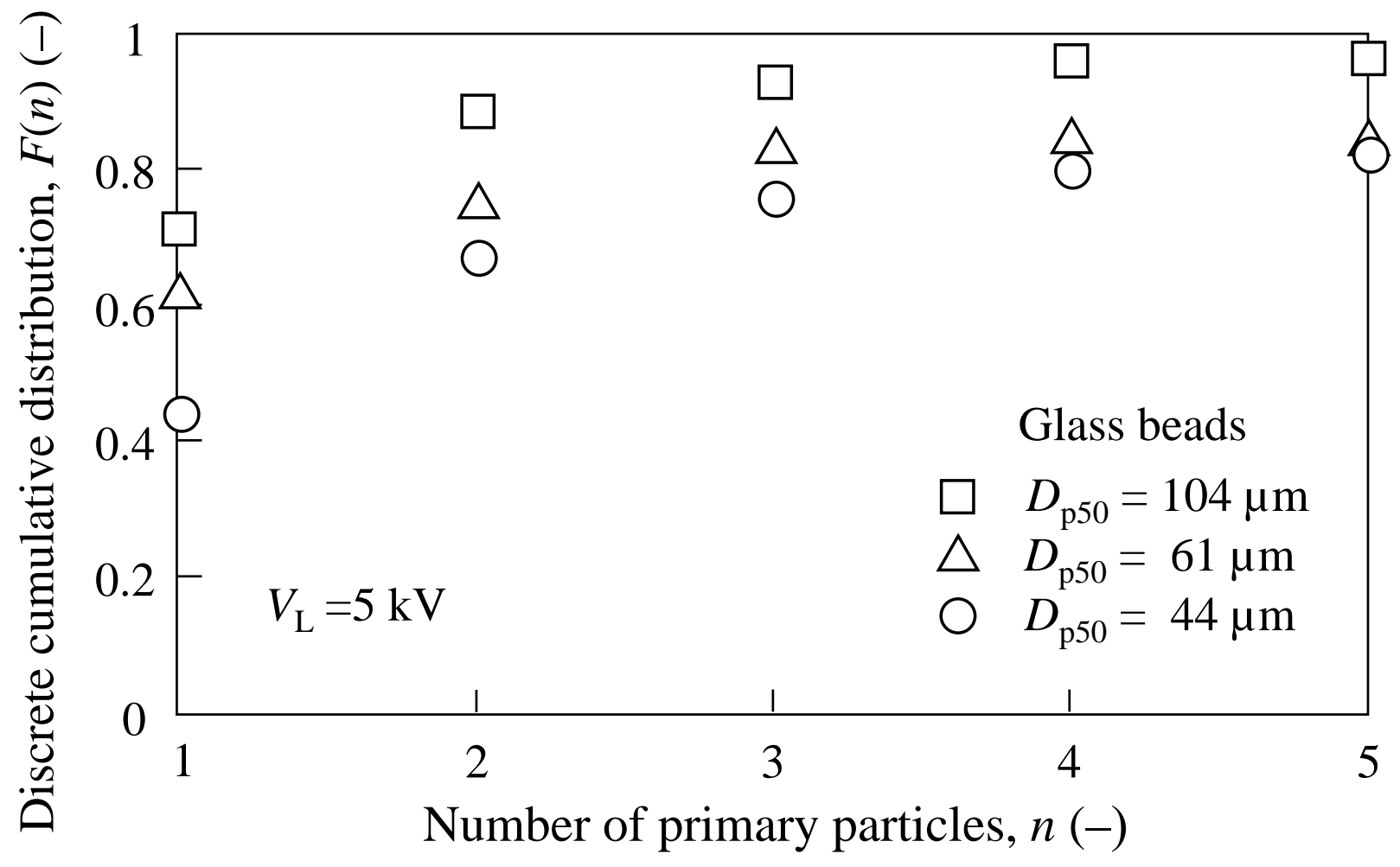

Fig. 5. Effect of primary particle diameter on the degree of agglomeration. 


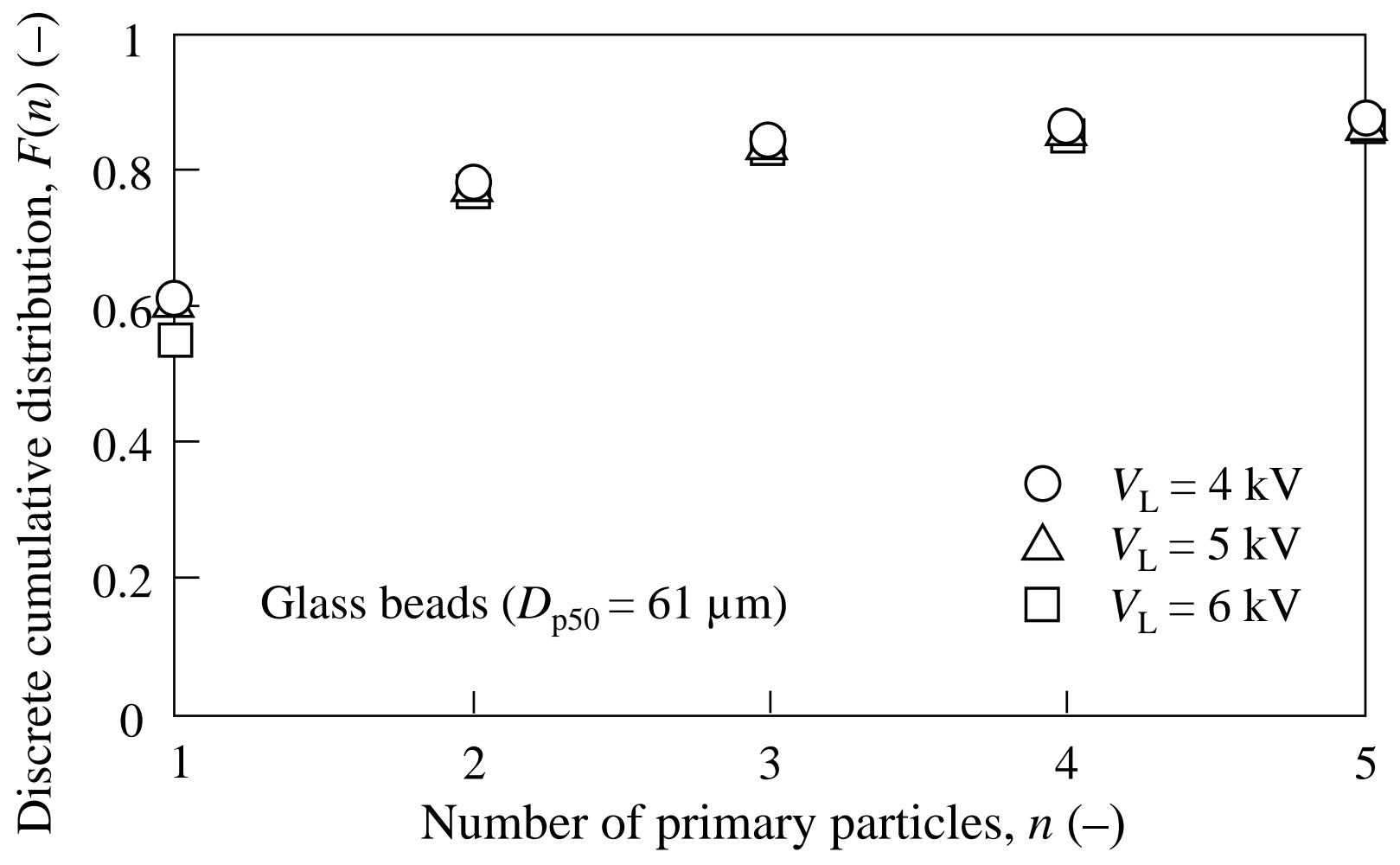

Fig. 6. Effect of applied voltage on the degree of agglomeration. 


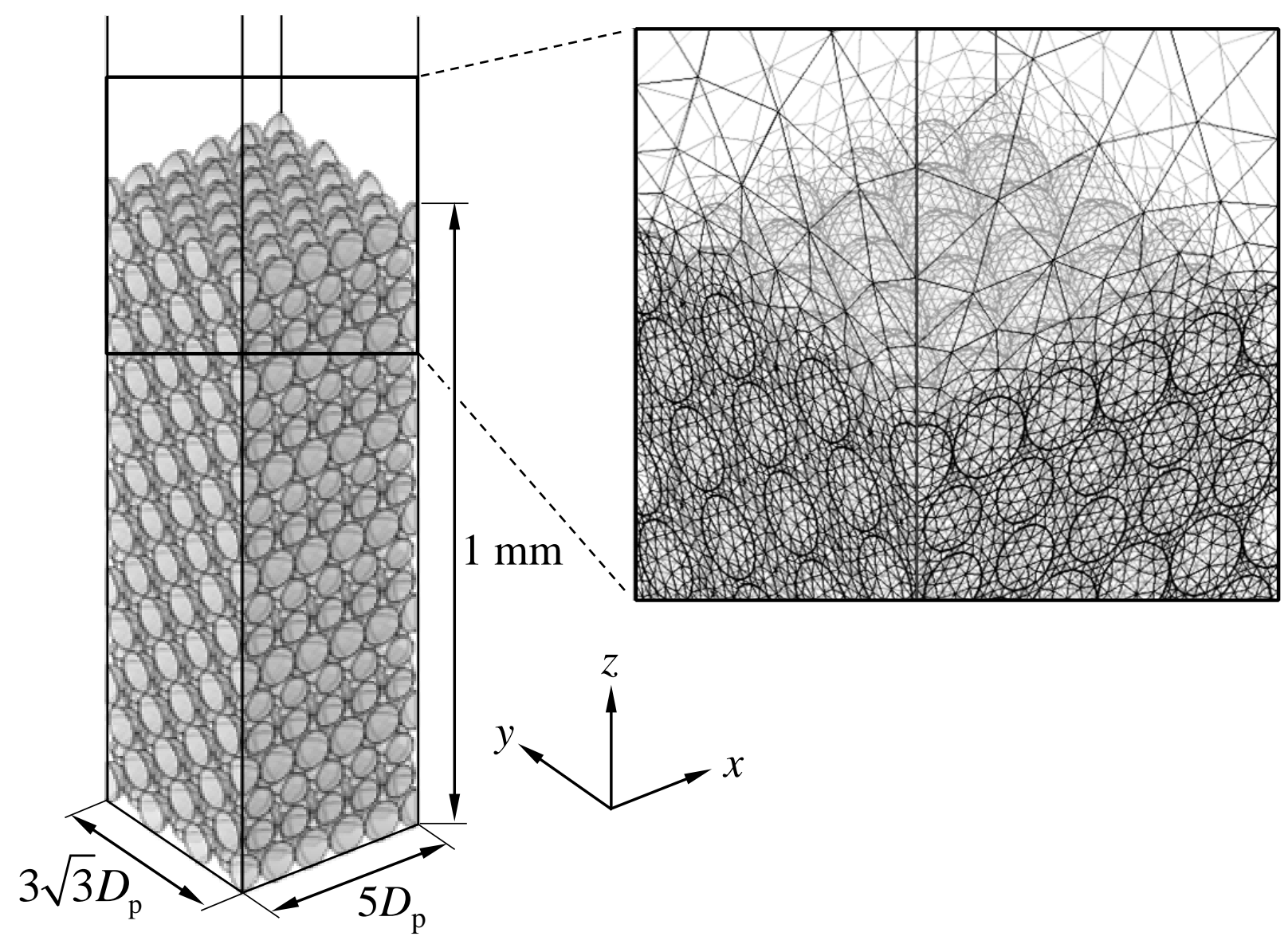

Fig. 7. Simulation model for calculating the electric field between electrodes with 1-mm-thick particle layers. 


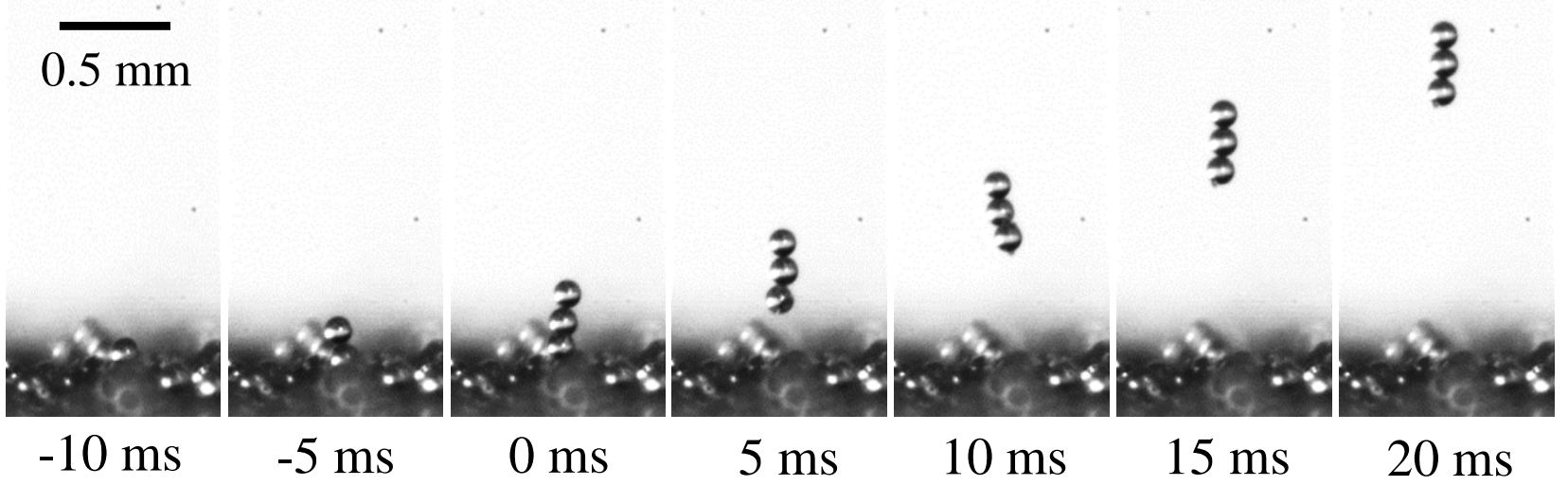

(a)

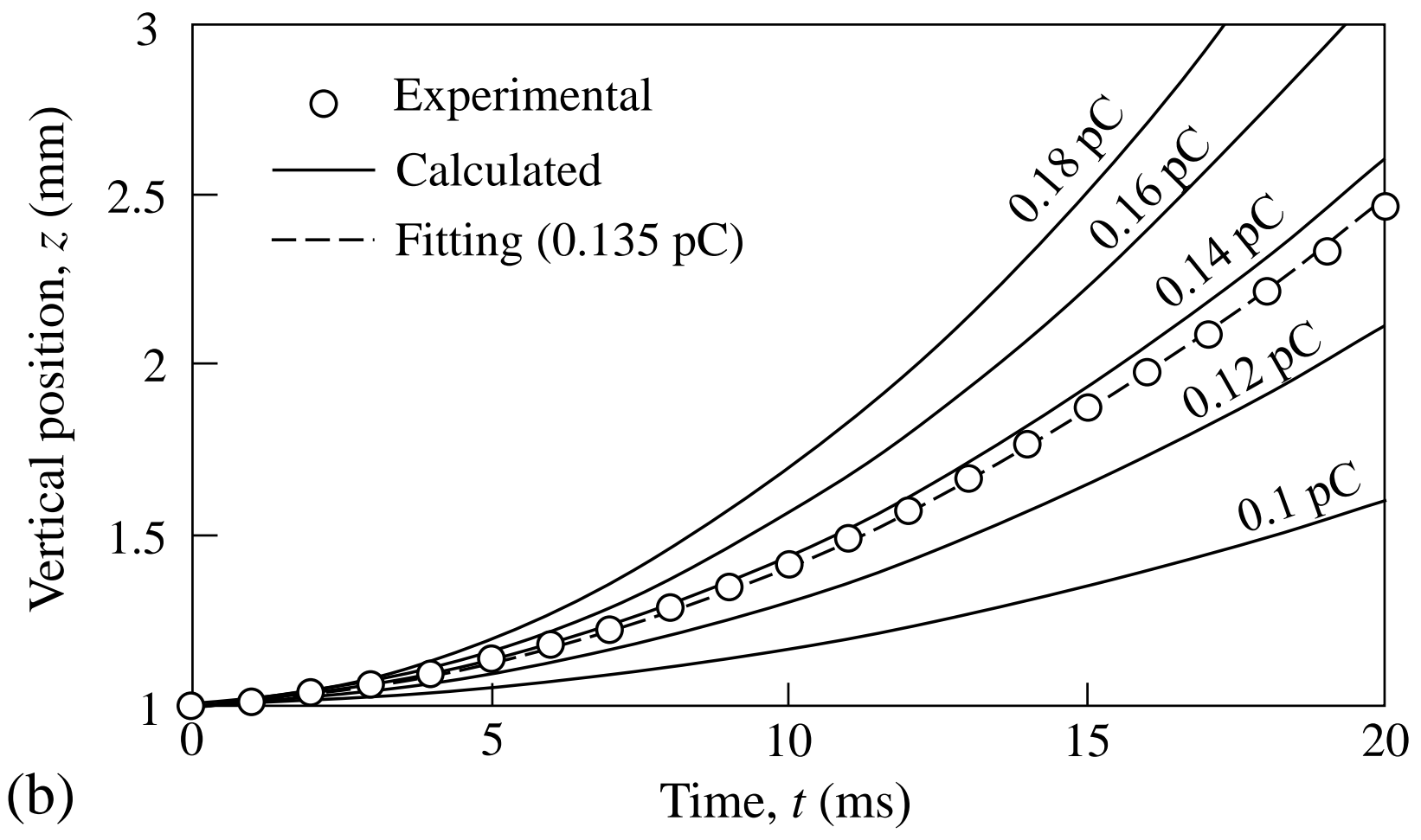

Fig. 8. Estimation of the charge of an agglomerate: (a) a series of images of the agglomeration of particles $(t \leq 0)$ and levitation $(t>0)$ from a 1-mm-thick particle layer (glass beads, $\left.D_{\mathrm{p}}=100 \mu \mathrm{m}\right)$ and (b) fitting of the experimental data related to levitation. 


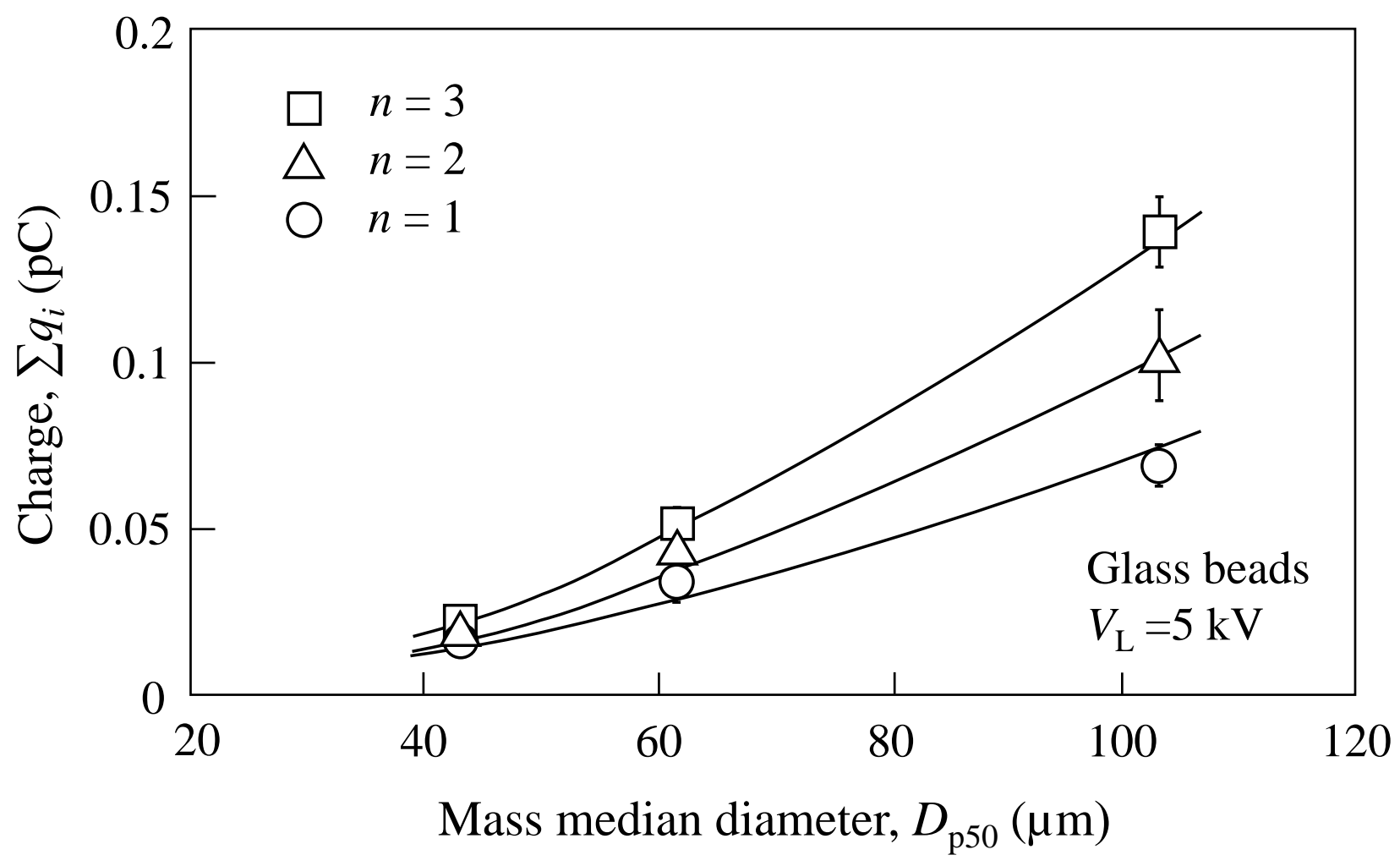

Fig. 9. Effect of particle diameter on the charge of an agglomerate or single particle. 


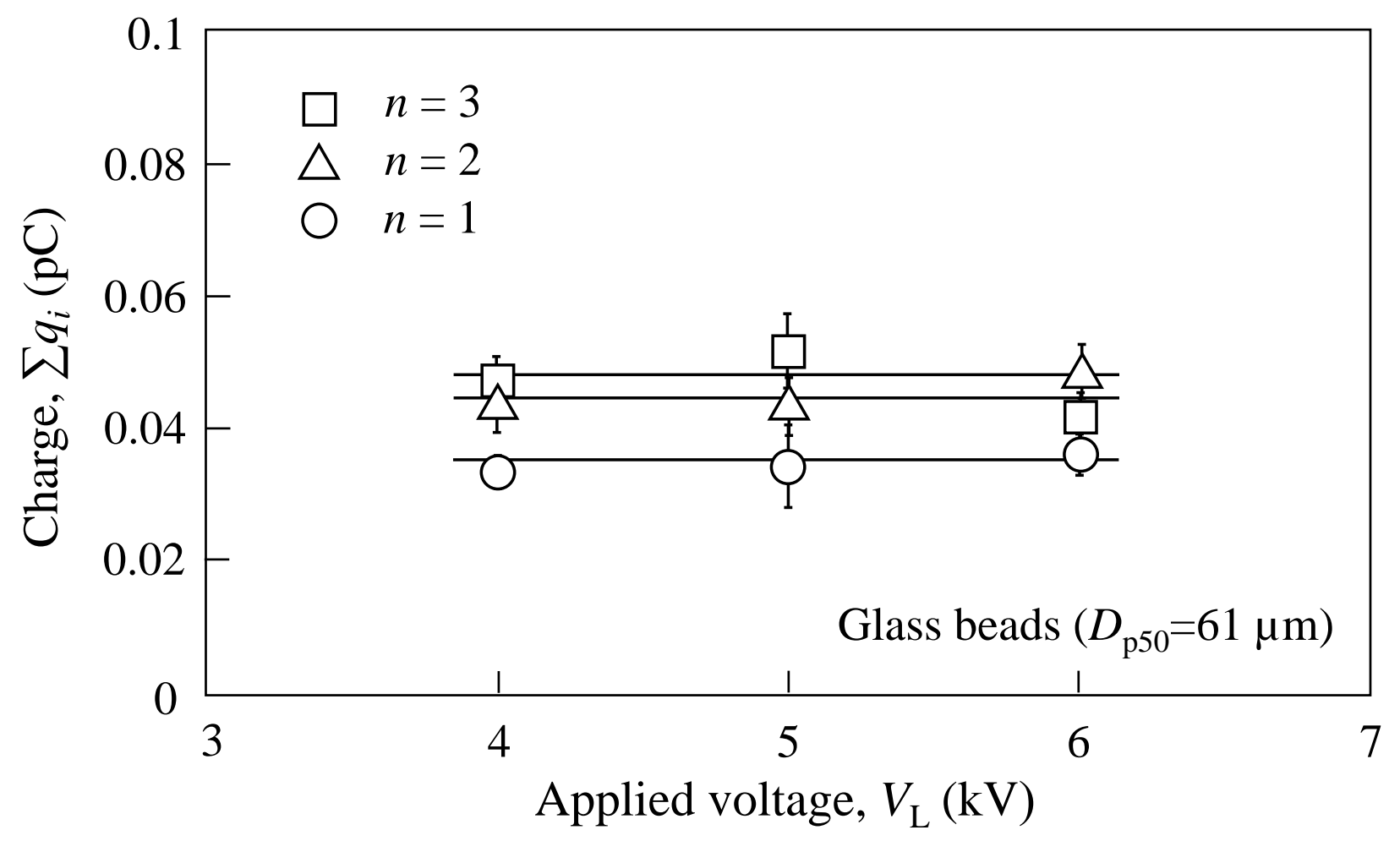

Fig. 10. Effect of applied voltage on the charge of particles constituting an agglomerate or single particle. 

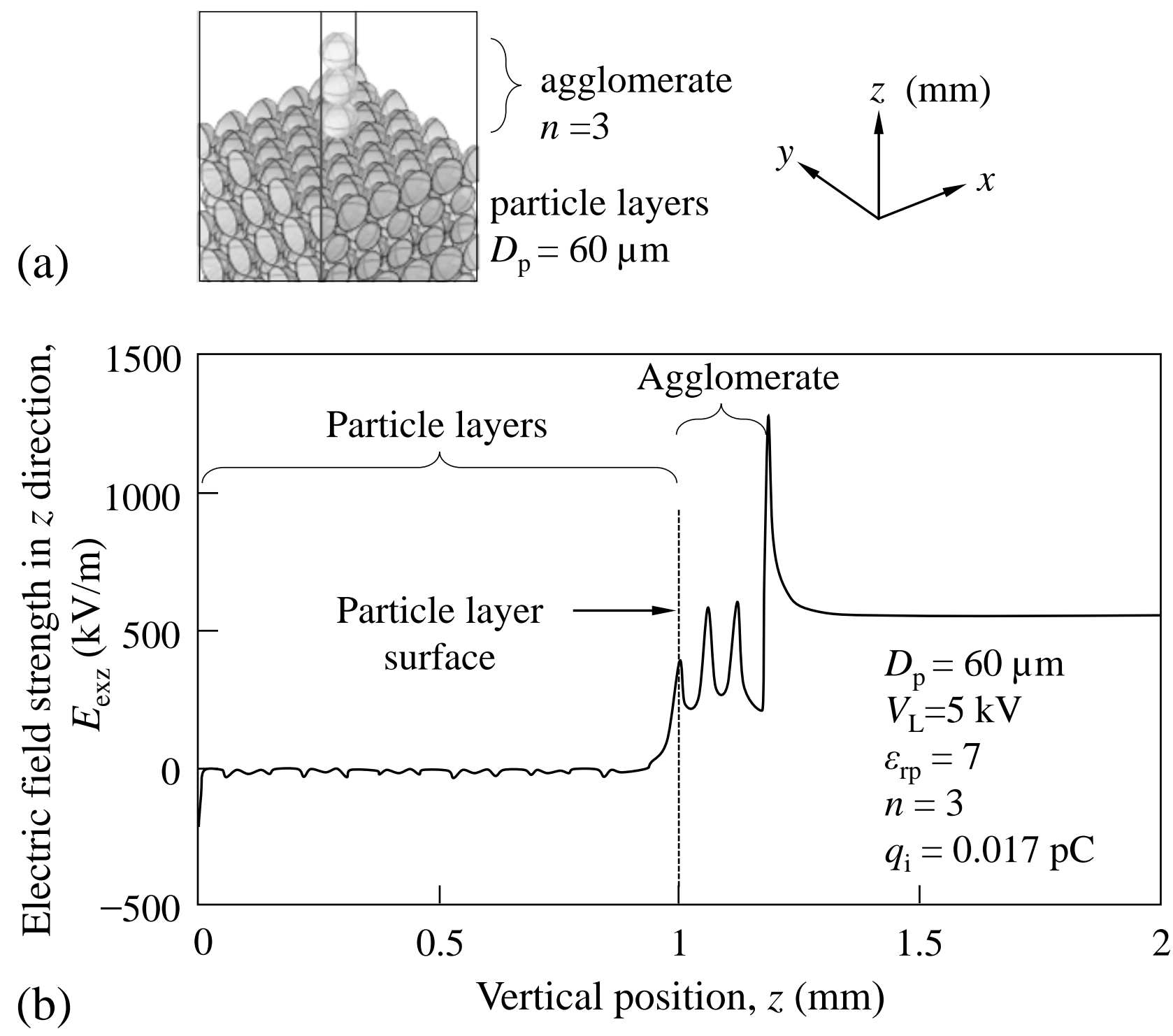

Fig. 11. Calculation of electric field strength: (a) simulation model and (b) calculated results in the $z$ direction along the axis of the chain agglomerate. 


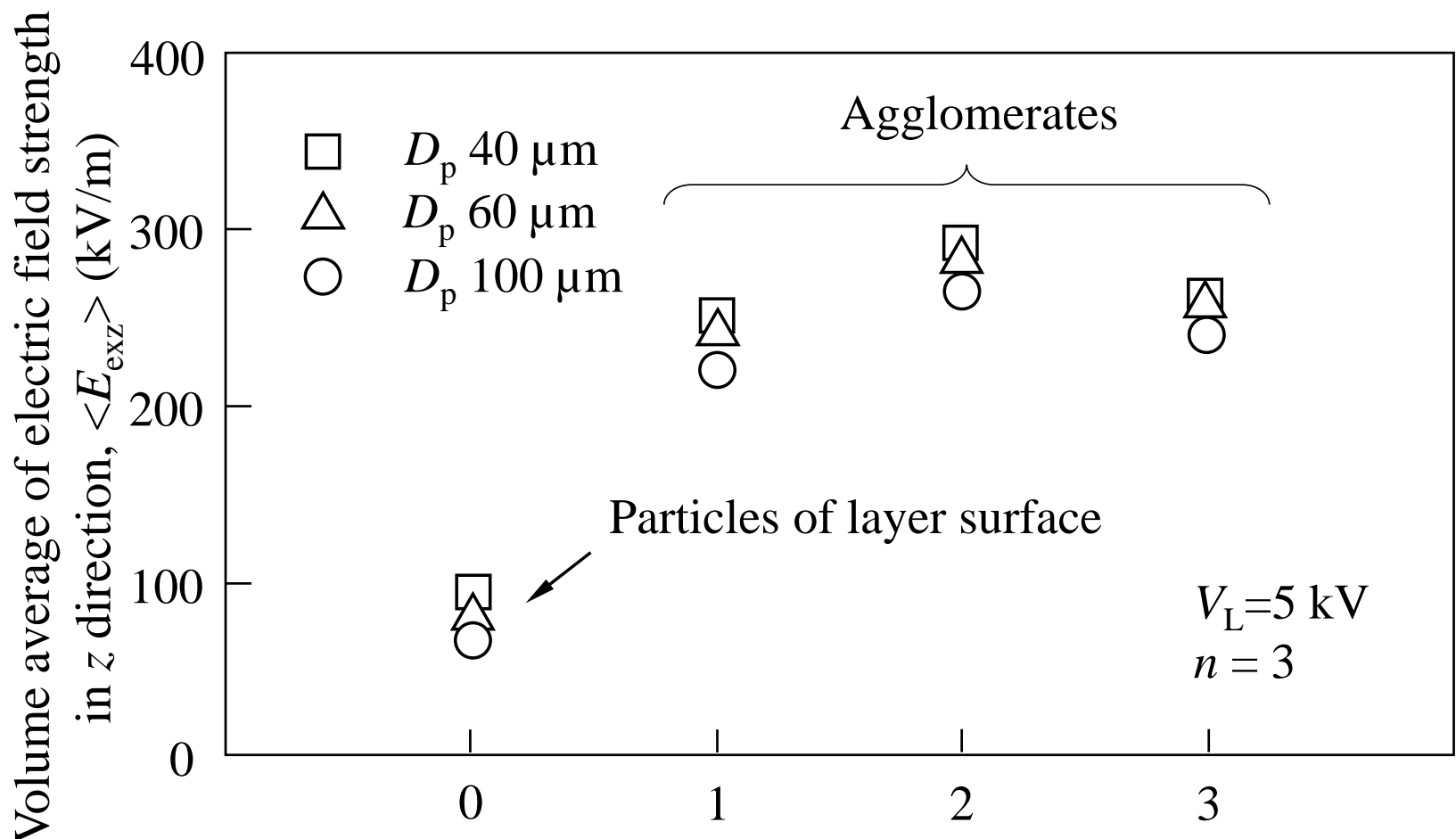

(a)

Ordinal number of particles, $n_{\mathrm{p}}(-)$

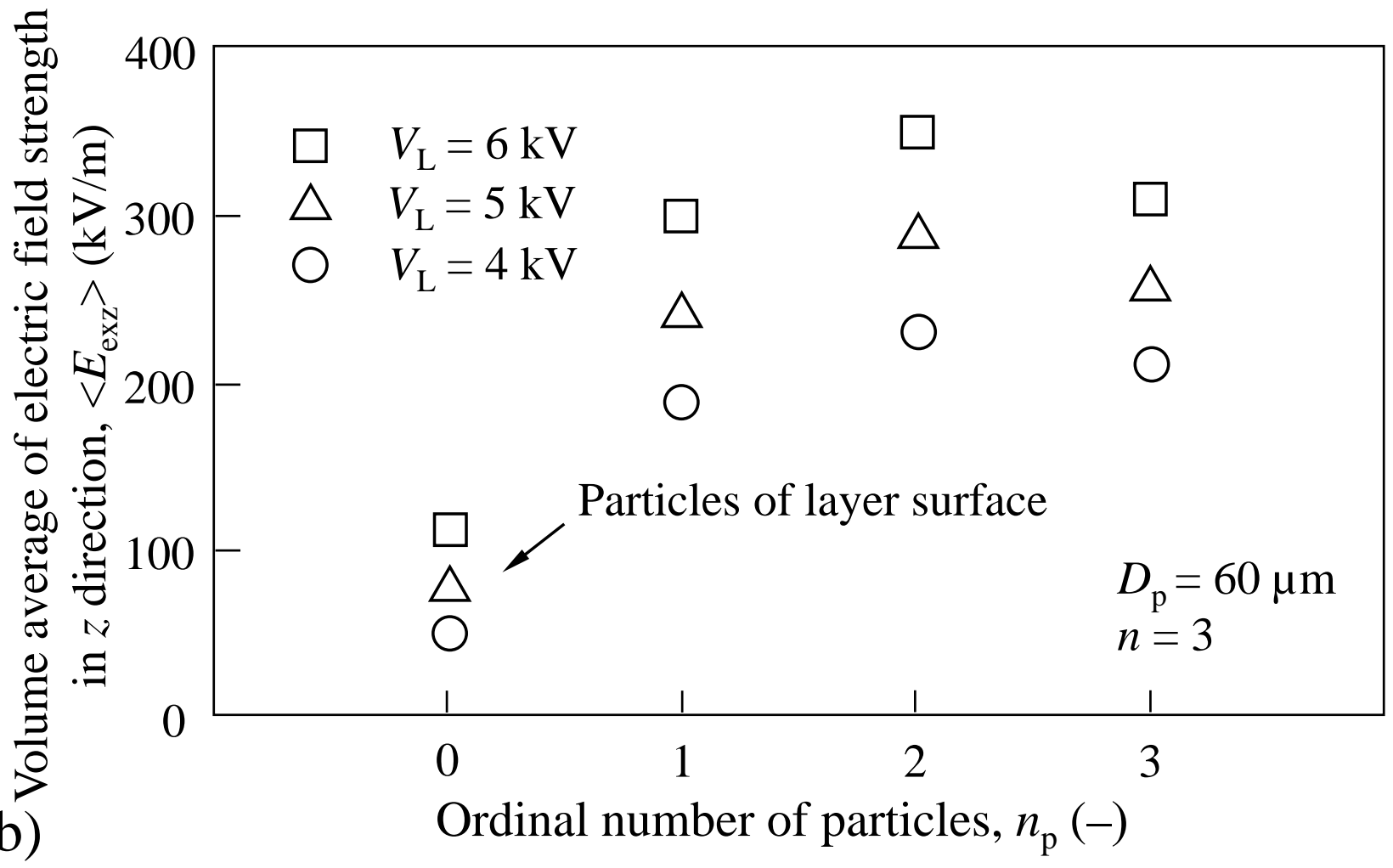

Fig. 12. Volume average of electric field strength in the $z$ direction for each particle in the chain agglomerate $\left(n_{\mathrm{p}}=1-3\right)$ and the top particles in the particle layers $\left(n_{\mathrm{p}}=0\right)$, where $n_{\mathrm{p}}$ is the ordinal number of particles, which is related to particle height: (a) effect of primary particle diameter $D_{\mathrm{p}}$ and (b) effect of applied voltage $V_{\mathrm{L}}$. 


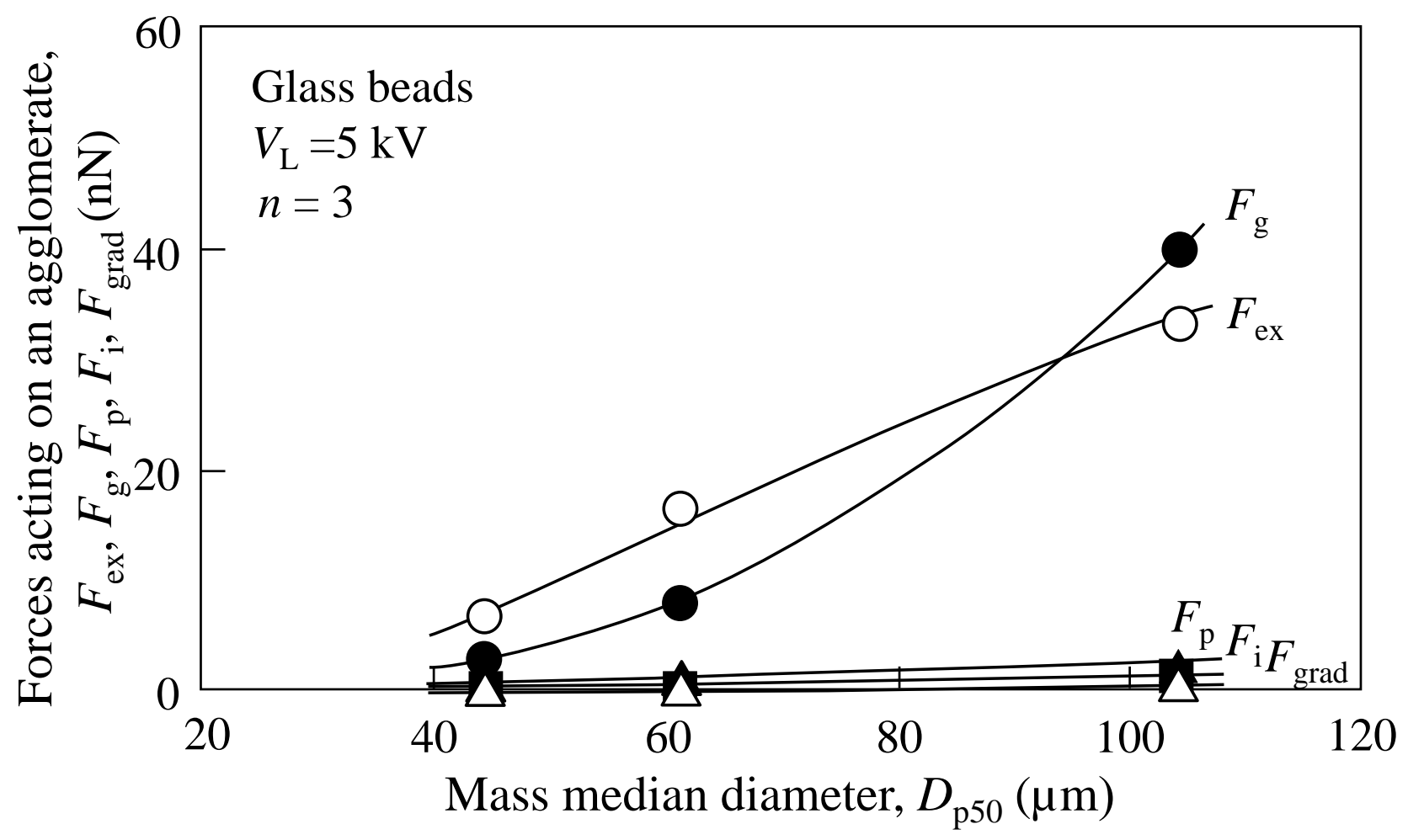

Fig. 13. Relationship between the forces acting on an agglomerate just prior to its separation from a particle layer and particle diameter. 


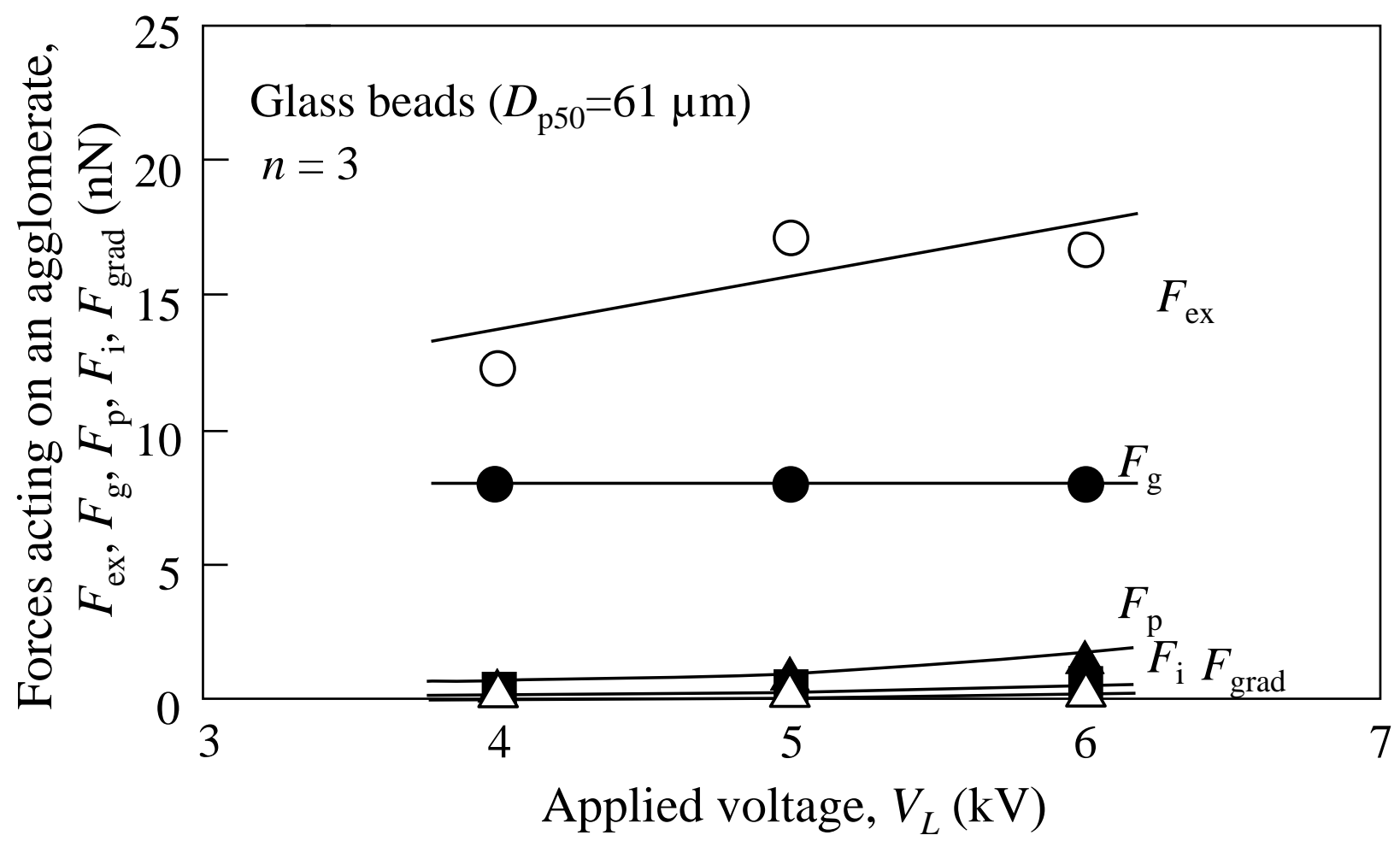

Fig. 14. Effect of applied voltage on the forces acting on an agglomerate just prior to its separation from a particle layer. 